\title{
EPISODIC MIGRAINE ASSOCIATED WITH POSTURAL ORTHOSTATIC TACHYCARDIA SYNDROME AND VASOVAGAL SYNCOPE
}

\author{
Migraine triggers neuromediated syncope
}

\author{
Elcio Juliato Piovesan', Claudia Ferreira Sobreira', Rosana Herminia Scola', Paulo José Lorenzoni', \\ Marcos Cristiano Lange', Lineu Cesar Werneck', Débora Smith', Stephen Silberstein ${ }^{4}$
}

Migraine is a common episodic headache disorder characterized by attacks consisting of various combinations of headache, neurologic, gastrointestinal and autonomic symptoms. Autonomic symptoms, such as a cold feeling, increased urination, anorexia, diarrhea, constipation and fluid retention', can occur during the premonitory phase, and nausea, vomiting, diarrhea, cutaneous vasoconstriction (pallor), vasodilation (flushing), piloerection and diaphoresis can occur during the pain phase $\mathrm{e}^{2}$. Migraine patients with accompanying autonomic symptoms seem to experience their pain more unilateral and more severe than non autonomic migraine patients. Studies of autonomic nervous system dysfunction in migraine have been performed ${ }^{2}$. Cardiovascular tests, vasomotor reactions to temperature changes and responses to pharmacological tests, and changes in biochemical parameters suggest abnormalities (hypo- or hyperfunctioning) of both the sympathetic and parasympathetic nervous systems $^{2}$. These inconsistent findings may be explained by different types of autonomic dysregulation. Syncope and migraine are both highly prevalent in the general population $^{3}$. Both disorders occur together more frequently than chance would predict ${ }^{3}$, i.e., they are comorbid. Studies using the orthostatic (tilt) test suggest that migraine patients have vagal hyperactivity and $\alpha$-sympathetic system hypoactivity ${ }^{2}$. Migraineurs may have a genetic predisposition leading to autonomic nervous system (ANS) dysfunction. The link between migraine and abnormal ANS function is unclear. ANS dysfunction may be involved in both increased susceptibility to migraine headaches and increased response to triggers. Migraine patients with typical autonomic symptoms, such as postural orthostatic tachycardia syndrome (POTS) and vasovagal syncope (VS), as well as patients with migraine with prolonged aura, are potential candidates for genetic studies ${ }^{4}$. Mitochondrial dysfunction may play a role in migraine pathophysiolo$\mathrm{gy}^{4-6}$. It is not known whether the mitochondrion (encoded by the nuclear and mitochondrial genomes) is the primary site of the dysfunction, or whether the mitochondrial disturbance occur secondary to another cause ${ }^{6}$. Mitochondria may play a role in the genesis of migraine, especially in these groups (migraine plus autonomic symptoms $)^{4,5}$. Connecting networks exist between pain and autonomic functions in the brain (Fig 1); thus pain can produce autonomic symptoms.

We describe a group of patients in whom autonomic symptoms (POTS and VS) occurred only during migraine attacks. We also studied the presence of the mitochondrial DNA (mtDNA) A3243G ${ }^{5}$ point mutation, common in patients with mitochondrial encephalomyopathy with lactic acidosis and stroke-like episodes (MELAS).

\section{METHOD}

Six patients with migraine attacks associated with postural orthostatic tachycardia syndrome followed by vasovagal syncope ( 4 females aged $28.05 \pm 8.21$ years and 2 males aged $31.21 \pm 5$ years) were selected from our migraine patient group $(n=3215)$. Only patients who had more than 20 percent of their migraine attacks associated with POTS and VS after the onset of pain were studied. Three patients had visual aura during some of their migraine attacks. The average age when they experienced their

MIGRÂNEA EPISÓDICA ASSOCIADA COM SÍNDROME DA TAQUICARDIA ORTOSTÁTICA POSTURAL E SÍNCOPE VASOVAGAL: MIGRÂNEA DESENCADEIA SÍNCOPE NEUROMEDIADA

${ }^{1}$ Neurology Service, ${ }^{3}$ Cardiology Service, Internal Medicine Department, Hospital de Clínicas, Federal University of Paraná (UFPR), Curitiba PR, Brazil; ${ }^{2}$ Department of Neurology, Psychiatry and Medical Psychology, Ribeirão Preto Faculty of Medicine, University of São Paulo (USP), Ribeirão Preto SP, Brazil; ${ }^{4}$ Jefferson Headache Center, Thomas Jefferson University Hospital, Philadelphia, PA, USA.

Received 2 August 2007, received in final form 29 November 2007. Accepted 5 January 2008.

Dr. Elcio Juliato Piovesan - Hospital de Clínicas da UFPR - Rua General Carneiro 181 / 12 andar / Sala 1236 - 80060-900 Curitiba PR - Brasil. E-mail: piovesan@avalon.sul.com.br 


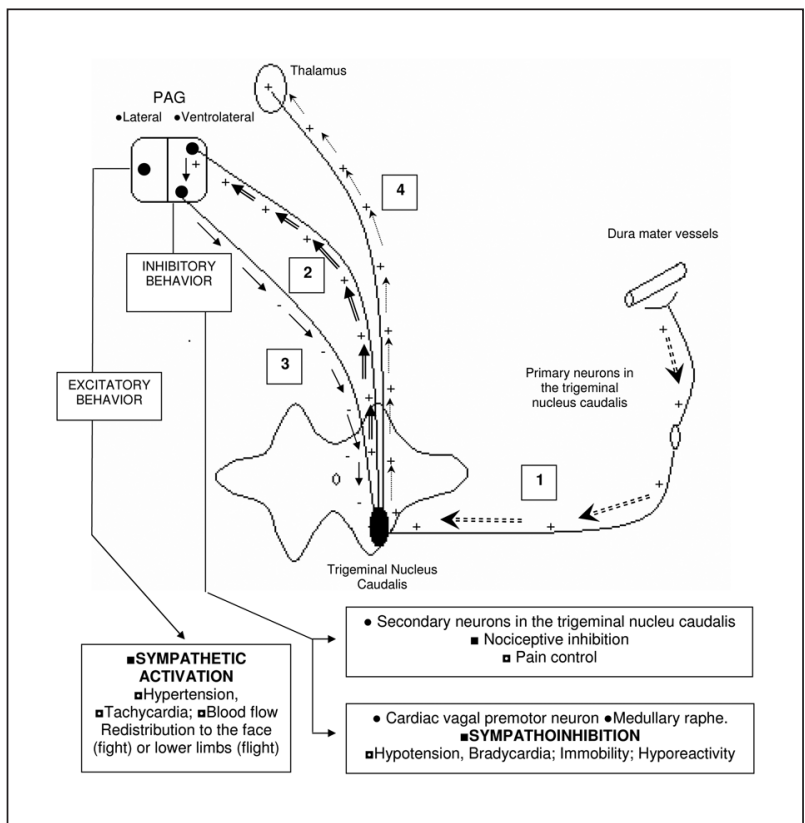

Fig 1. Interaction between migraine and autonomic symptoms: (Step 1) primary nociceptive activation of the dura mater; (Step 2) activation of the ventrolateral periaqueductal gray substance (PAG); (Step 3) inhibitory behavior of the ventrolateral PAG over the trigeminal nucleus caudalis; (Step 4) balance between different excitatory and inhibitory potentials and activation of the thalamus.

first attack was $17.23 \pm 3.20$ years; the average number of attacks was $2.3 \pm 1.2$ per month. Patients with other autonomic symptoms or with isolated POTS, isolated VS, or POTS plus VS not associated with migraine were excluded. All six patients were studied using brain magnetic resonance imaging, electroencephalograms, tilt-table test and analysis of the A3243G point mutation in mitochondrial DNA (mtDNA).
Tilt protocol consisted in $70^{\circ}$ angulation during 30 minutes after a supine rest for 10 minutes. A positive result during tilt-table test was considered according to the literature ${ }^{7,8}$. Analysis of the A-to-G mutation at position 3243 of the mtDNA was done by the PCR-RFLP (polymerase chain reaction/restriction fragment length polymorphism) method using DNA from peripheral blood lymphocytes, as previously described ${ }^{3,9}$. The control group for DNA mutation consisted of two patients with MELAS. Prophylactic treatment for migraine was not used during the investigation protocol. All subjects provided written informed consent, as required by appropriate local (Human Ethical committee of Universidade Federal do Paraná) committees on the protection of research subjects.

\section{RESULTS}

All patients had normal MRIs and electroencephalograms. All patients had POTS and subsequent VS during the tilt-table test without pharmacologic induction. The average time to onset of symptoms was $16.4 \pm 5.2 \mathrm{~min}-$ utes. Only two patients had headache during the tilt-table test. Both cases related that headache is different of the usual migraine attacks. We found an association between migraine, POTS and VS in $0.18 \%$ of our migraine patients. The A3243G mutation was not detected by the PCR-RFLP method in our six migraineurs with migraine/POTS/VS, but was detected in the two MELAS patients in the control group (see Table, Figs 2 and 3).

\section{DISCUSSION}

Our group of migraine patients present autonomic symptoms such as POTS and VS after pain onset. DNA studies showed that the $\mathrm{A} 3243 \mathrm{G}$ point mutation was not

Table. Case descriptions: clinical features; headache intensity measured according to the visual analogue scale (VAS); frequency (in percent) of postural orthostatic tachycardia syndrome (POTS) and vasovagal syncope (VS) symptoms; results of the tilt-table test and time to onset of autonomic symptoms; and results of DNA testing (see Fig 1).

\begin{tabular}{|c|c|c|c|c|c|c|c|c|}
\hline Case & Gender & Age & $\begin{array}{c}\text { Age at } \\
\text { first attack } \\
\text { (years) }\end{array}$ & $\begin{array}{c}\text { Attacks } \\
\text { per month }\end{array}$ & $\begin{array}{c}\text { First } \\
\text { symptoms } \\
\text { VAS }\end{array}$ & $\begin{array}{c}\text { Frequency of } \\
\text { subsequent } \\
\text { symptoms }\end{array}$ & Tilt-table test & $\begin{array}{c}\text { DNA } \\
\text { (A3243G point } \\
\text { mutation) }\end{array}$ \\
\hline 1 & Female & 36 & 16 & 3 & $\begin{array}{l}\text { Headache } \\
\text { (VAS-8) }\end{array}$ & $\begin{array}{c}25 \% \text { POTS } \\
\text { and VS }\end{array}$ & $\begin{array}{c}\text { Positive } \\
20 \text { min after }\end{array}$ & Absent \\
\hline 2 & Female & 19 & 14 & 2 & $\begin{array}{l}\text { Headache } \\
\text { (VAS-9) }\end{array}$ & $\begin{array}{c}22 \% \text { POTS } \\
\text { and VS }\end{array}$ & $\begin{array}{c}\text { Positive } \\
18 \text { min after }\end{array}$ & Absent \\
\hline 3 & Female & 22 & 16 & 4 & $\begin{array}{l}\text { Headache } \\
\text { (VAS-9) }\end{array}$ & $\begin{array}{c}29 \% \text { POTS } \\
\text { and VS }\end{array}$ & $\begin{array}{c}\text { Positive } \\
15 \text { min after }\end{array}$ & Absent \\
\hline 4 & Female & 35 & 21 & 3 & $\begin{array}{l}\text { Headache } \\
\text { (VAS-10) }\end{array}$ & $\begin{array}{c}31 \% \text { POTS } \\
\text { and VS }\end{array}$ & $\begin{array}{c}\text { Positive } \\
18 \text { min after }\end{array}$ & Absent \\
\hline 5 & Male & 36 & 11 & 2 & $\begin{array}{l}\text { Headache } \\
\text { (VAS-8) }\end{array}$ & $\begin{array}{c}24 \% \text { POTS } \\
\text { and VS }\end{array}$ & $\begin{array}{c}\text { Positive } \\
22 \text { min after }\end{array}$ & Absent \\
\hline 6 & Male & 24 & 22 & 2 & $\begin{array}{l}\text { Headache } \\
\text { (VAS-8) }\end{array}$ & $\begin{array}{c}22 \% \text { POTS } \\
\text { and VS }\end{array}$ & $\begin{array}{c}\text { Positive } \\
27 \text { min after }\end{array}$ & Absent \\
\hline
\end{tabular}




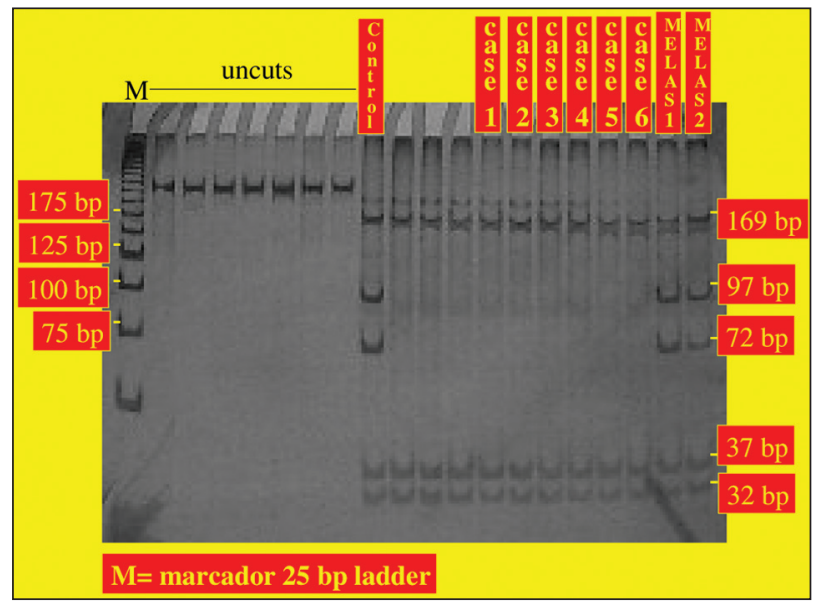

Fig 2. PCR-RFLP analysis to detect the A3243G mutation showed that the it was absent in the six migraineurs with POTS and VS but was present in the two MELAS control subjects.

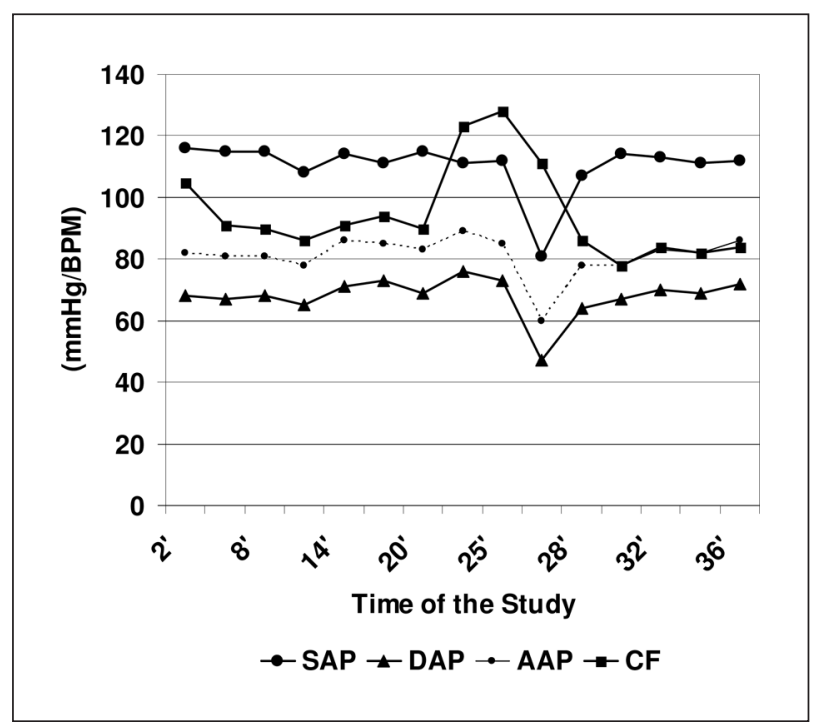

Fig 3. Tilt-table test; SAP, systolic arterial pressure; DAP, diastolic arterial pressure; $A A P$, average arterial pressure; $C F$, cardiac frequency.

present in these patients. Why patients develop autonomic symptoms, such as vasovagal syncope, during migraine attacks is not clear ${ }^{3}$. A small subset of patients develop autonomic disorders only after the onset of migraine headache. In these patients migraine pain probably triggers neuromediated syncope (Table). Autonomic-nervoussystem-related syncope is common, with a life prevalence of $46 \%$ in migraineurs ${ }^{10}$. This can be confused with epilepsy. We have shown that migraine patients can develop loss of consciousness as a result of neuromediated syncope (Fig 1).

The association between migraine and abnormal mitochondrial function has been suggested on clinical, biochemical and neuroradiological grounds'. A few studies have examined mtDNA mutations in high risk subgroups of migraineurs: patients with migraine with or without aura selected from pedigrees with a maternal mode of transmission, patients with cluster headache, patients with migrainous cerebral infarction, and patients with sporadic hemiplegic migraine $e^{4,6}$.

Most but not all studies have not detected mtDNA mutations in migraine patients ${ }^{4,11}$. Despite the negative results, some speculate that mtDNA mutations could contribute to the pathogenesis of migraine ${ }^{4}$.

We looked for, but did not find any mtDNA MELAS A3243G point mutation, the most common mutation in mitochondrial diseases. MELAS typically presents with severe migraine-like symptoms, and the A3243G mutation was previously found in $6 \%$ of migraine patients from another subgroup (with juvenile occipital migraine stroke) ) $^{3-5,12,13}$.

The physiologic link between migraine and autonomic dysfunctions probably occurs in the PAG (specifically, in the ventrolateral region) and hypothalamus. Nociceptive input may, trigger an inhibitory reaction from the PAG to the trigeminal nucleus caudalis, triggering secondary sympathoinhibition. In our study, $0.18 \%$ of the migraine patients had coexistant POTS and VS during their migraine attacks. No mitochondrial dysfunction (mtDNA A3243G point mutation) was detected in this group.

\section{REFERENCES}

1. Silberstein SD, Saper JR, Freitag FG. Migraine: diagnosis and treatment. In Silberstein SD, Lipton RB, Dalessio DJ (Eds). Wolff's headache and other head pain. Seventh edition. New York: Oxford University Press, 2001:101-237.

2. Benjelloun H, Birouk N, Slaoui I et al. Autonomic profile of patients with migraine. Neurophysiol Clin 2005;35:127-134.

3. Brignole M, Alboni P, Benditt DG et al. Guidelines on management (diagnosis and treatment) of syncope - update 2004. Europace 2004;6:467-537.

4. Montagna P. Molecular genetics of migraine headaches: a review. Cephalalgia 2000;20:3-14.

5. Di Gennaro G, Buzzi MG, Ciccarelli O, et al. Assessing the relative incidence of mitochondrial DNA A3243G in migraine without aura with maternal inheritance. Headache 2000;40:568-571.

6. Haan J, Terwindt GM, Maassen JA, et al. Search for mitochondrial DNA mutations in migraine subgroups. Cephalalgia 1999;19:20-22.

7. Brignole M, Menozzi C, Del Rosso A, et al. New classification of haemodynamics of vasovagal syncope: beyond the VASIS classification. Europace 2000;2:66-76.

8. Grubb BP, Kanjwal MY, Kosinski DJ. Review: the postural orthostatic tachycardia syndrome: current concepts in pathophysiology, diagnosis and management. J Interv Card Electrophysiol 2001;5:9-16.

9. Obermann M, Yoon MS, Dommes P et al. Prevalence of trigeminal autonomic symptoms in migraine: a population-based study. Cephalalgia 2007;27:504-509.

10. Thijs RD, Kruit MC, van Buchem MA, et al. Syncope in migraine: the population-based CAMERA study. Neurology 2006;66:1034-1037.

11. Rozen TD, Shanske S, Otaegui D, et al. Study of mitochondrial DNA mutations in patients with migraine with prolonged aura. Headache 2004;44:674-677.

12. Majamaa K, Turkka J, Karppa M, Winqvist S, Hassinen IE. The common MELAS mutation A3243G in mitochondrial DNA among young patients with an occipital brain infarct. Neurology 1997;49:1331-1334.

13. Ciafaloni E, Ricci E, Shanske S, et al. MELAS: clinical features, biochemistry, and molecular genetics. Ann Neurol 1992;31:391-398. 